\title{
Atividade social acadêmica no ensino de língua inglesa on-line: o que os aprendizes nos dizem sobre isso? ${ }^{1}$
}

\section{Academic social activity in online English language teaching: what do learners tell us about it?}

Julia Larré*

*Universidade Federal Rural de Pernambuco (UFRPE), Recife, Pernambuco/Brasil jlarre1304@gmail.com

\begin{abstract}
RESUMO: Neste artigo propomos compreender, por meio do discurso dos participantes, o impacto do planejamento (ALMEIDA FILHO, 2012) de um curso de língua inglesa on-line em contexto universitário, baseado em Atividades Sociais (LIBERALI, 2012). Para isso, explanamos brevemente a Teoria da Atividade Sócio-Histórico-Cultural (ENGESTRÖM, 1999) e a noção de Atividades Sociais no ensino de língua inglesa como formas de permitir o reposicionamento social dos aprendizes, mesmo através de um ambiente de ensino-aprendizagem virtual. Demonstramos como o curso foi planejado e analisamos aspectos relativos à desenvoltura e às dificuldades dos aprendizes, sua qualidade de participação e suas percepções sobre o curso. Como resultados, verificamos que os aprendizes em geral possuem dificuldades com Atividades Sociais de cunho acadêmico e que estas dificuldades resultaram em participação limitada nas atividades didáticas propostas no curso. No entanto, aspectos positivos foram observados pela professora-pesquisadora e citados pelos alunos em seus depoimentos.
\end{abstract}

PALAVRAS-CHAVE: ensino de língua inglesa; EaD; Atividades Sociais; TASHC; planejamento.

ABSTRACT: In this article we seek to understand, through the participants' discourse, the impact of the planning (ALMEIDA FILHO, 2012) of an online English language course in a university context, based on Social Activities (LIBERALI, 2012). To do so, we briefly explain the Socio-Cultural-Historical Activity Theory (ENGESTRÖM, 1999) and the notion of Social Activities in

\footnotetext{
${ }^{1}$ Trabalho decorrente de recorte de pesquisa de pós-doutoramento (Capes-PNPD) realizada no Programa de Pós-graduação em Linguística da Universidade Federal de São Carlos (PPGL-UFSCar), sob supervisão da professora dra. Rita de Cássia Barbirato.
} 
English teaching as a way to enable the social repositioning of learners, even through an environment of online teaching and learning. We show how the course was planned and also analyze aspects related to learners' performances and difficulties, the quality of their participation and their perceptions of the course. As a result, we verified that the learners in general have difficulties with Social Activities of an academic nature and that these difficulties led to limited participation in the didactic activities proposed in the course. However, positive aspects were observed by the teacher-researcher and cited by the students in their testimonies.

KEYWORDS: English language teaching; distance learning; Social Activities; SCHAT; planning.

\section{Introdução}

Este artigo é um recorte de pesquisa de pós-doutorado realizada sobre ensino-aprendizagem de língua inglesa (LI) no contexto da educação a distância (EaD). A expansão da $\mathrm{EaD}$ no contexto universitário brasileiro trouxe necessidades específicas também ao processo de ensino-aprendizagem de língua estrangeira, em nosso caso a LI, pois este é um dos idiomas que variados cursos universitários oferecem a seus alunos. O maior desafio, pois, para o professor conteudista de LI nos ambientes virtuais de ensinoaprendizagem (Avea) é planejar cursos que promovam a aprendizagem significativa e reflexiva através do uso potencial que as tecnologias digitais de informação e comunicação (TDIC) oferecem, atendendo às necessidades dos alunos dos diversos cursos que possuem LI como disciplina obrigatória, eletiva ou optativa, ou como curso de extensão.

Leffa (2005) afirmava há algum tempo que há poucas pesquisas que exploram novas possibilidades de condições de aprendizagem nessa seara. Essa realidade ainda pode ser averiguada, já que alguns dos relevantes estudos que encontramos até então que tratam do ensino de LI na EaD (BOETTCHER, 2008; ESTIVALET, 2012; ESTIVALET; HACK, 2011; SILVEIRA, 2015) se restringem à análise discursiva da interação professoraluno no AVA, a estudos que utilizam o computador e a internet como auxiliares no processo de aprendizagem (FIGUEIREDO, 2015), ou à elaboração de aplicativos que facilitem a aquisição de estruturas gramaticais e vocabulares (LEVAY, 2015; RODRIGUES, 2014).

Antes de mais nada, reiteramos que essa é uma investigação inserida no domínio da Linguística Aplicada (MOITA LOPES, 2013), que se trata de um campo teórico e prático no qual ser capaz de questionar, analisar, refletir e de 
intervir de maneira a transformar o presente da sala de aula é perfeitamente aceitável e desejável. No Brasil, de acordo com Moita Lopes (2013, p. 17), esse campo de estudos é quase completamente "de natureza qualitativa, com preocupações sobre o idiossincrático, o particular e o situado”, justificando, assim, a natureza desta pesquisa de pós-doutorado. Posicionamo-nos, pois, em uma área de conhecimento que se insere em uma seara de movimento contínuo, na qual o pesquisador está sempre "questionando-se, apostando nesse percurso nômade como estímulo ao desejo de curiosidade e criação, de pensar o impensado e de, apoiando-se no conhecido, torná-lo outro e estranhá-lo, para ousar ultrapassá-lo" (FABRÍCIO, 2006, p. 61) e objetivar uma vida melhor. Nesse sentido, aqui demonstramos nossa preocupação, dentro dessa ótica da LA, com a

[...] necessidade urgente de teorizações que estabeleçam diálogo com o mundo contemporâneo e com as práticas sociais reais dos sujeitos que vivem a linguagem em uma sociedade atravessada pela globalização, acesso à comunicação e inserida em múltiplas possibilidades semióticas de construir significado sobre o mundo (DIAS, 2018).

Estar presente no mundo contemporâneo significa, inclusive, estar atento às práticas de linguagem e (multi)letramentos vigentes. Justificamos, desse modo, a escolha pelo planejamento de curso inserido na $\mathrm{EaD}$, que, apesar de ter tido no Brasil a sua implementação em todas as universidades por meio da Universidade Aberta do Brasil, permanece como modalidade de ensino-aprendizagem ainda insuficientemente explorada no que tange às práticas de língua estrangeira.

Concordamos também com Almeida Filho (2012), que nos diz que a tarefa de planejar um curso de língua justifica-se como objeto de pesquisa por estar inserida no âmbito da LA, e especialmente por se preocupar com o estudo de questões que englobam o uso social da linguagem na prática.

É igualmente importante mencionar que nossa investigação possuiu como pressuposto uma visão de ensino e aprendizagem de língua estrangeira baseados em uma perspectiva sócio-histórico-cultural (ENGESTRÖM, 1999; LIBERALI, 2009), em que podem ser realizados estudos sobre os "sujeitos que se encontram em interação com os outros, em contextos culturais específicos e dependentes historicamente" (LARRÉ, 2014, p. 32). Nesses contextos, surgem necessidades que também envolvem o aprendizado de uma língua estrangeira, de modo que é possível abordarmos 
o ensino-aprendizagem como, além de uma forma de oportunizar a comunicação, proporcionar a possibilidade de compreensão e transformação do mundo e as vivências na interação com outras culturas e em contextos diferentes do que o sujeito geralmente vive.

Consonante ao que vimos acima, observamos que é perfeitamente possível integrar o ensino de língua inglesa com base em Atividades Sociais (AS) - que se tratam de concretizações do agir humano e sobre as quais discorreremos mais adiante com detalhamento -, pautadas pela vida real, de modo que os sujeitos envolvidos

[...] sejam responsáveis por estabelecer mudanças no seu contexto e na sociedade de maneira geral e essa capacidade de reconstrução de uma realidade é para os sujeitos como uma mola propulsora que os impulsiona a sonhar e a desejar mudar suas condições de vida, buscando uma maior participação social como cidadãos na esfera acadêmica (RICHTER, 2015, p. 62).

Para definir a AS que os aprendizes deveriam realizar, consideramos a noção de que o ensino de língua estrangeira deve ser planejado como maneira de contribuir na formação do indivíduo. Além disso, pensamos no fato de que atividades de "inserção na vida cultural que perpassam questões de linguagem" (LIBERALI, 2009, p. 16) permitem que os sujeitos transformem suas ações na AS proposta em "objetos de reflexão e apropriação de formas de ação de discussão sobre a forma como a linguagem veicula ideias e sugere aspectos de vida" (LIBERALI, 2009, p. 16). Segundo Richter (2015, p. 56), "é participando de Atividades Sociais que os alunos (re)constroem a sua identidade e pensam em novos modos de agir". Isso tudo na modalidade a distância, proporcionando o desenvolvimento do "trabalho cooperativo, o aprender a aprender, a habilidade de tomar decisões, de processar e criar conhecimento" (PAIVA, 1999) através de vivências que possibilitem o aprendiz a desenvolver a autonomia, a responsabilidade e a responsividade em situações com as quais ele irá se deparar no mundo.

$\mathrm{Na}$ fundamentação teórica, iremos abordar brevemente aspectos teórico-filosóficos que nortearam a pesquisa que deram origem a este artigo, definindo os eixos de nosso trabalho, especialmente relacionados com as temáticas de ensino-aprendizagem de LI na EaD, planejamento de cursos de línguas e questões relativas ao planejamento de AS na sala de aula de LI. Na seção sobre a metodologia da pesquisa, demonstraremos resumidamente 
como o planejamento do curso de LI na plataforma virtual foi realizado, considerando os aspectos fundamentais para o ensino-aprendizagem baseado em AS. Em seguida, analisaremos o impacto da experiência didática realizada através dos depoimentos que os próprios sujeitos participantes deram durante os fóruns realizados na disciplina on-line.

\section{A Teoria da Atividade Sócio-Histórico-Cultural como um eixo norteador da experiência}

A Teoria da Atividade Sócio-Histórico-Cultural - TASHC (ENGESTRÖM, 1999) pode ser definida como o estudo das atividades realizadas por sujeitos que se encontram em interação com outros, em contextos culturais específicos e dependentes historicamente. A TASHC está ancorada no materialismo histórico-dialético (MARX; ENGELS, 2006), pois considera a práxis como uma possibilidade do desenvolvimento de aspectos históricos e sociais do ser humano e também de seu desenvolvimento como indivíduo.

Recorremos a Schettini (2009), que afirma que a TASHC é considerada como uma perspectiva que

não percebe a atividade humana como um sistema de atividades isoladas, mas sim como uma rede de relações culturais que, através do diálogo e da colaboração, possui uma função transformadora ao enfatizar a noção de historicidade (SCHETTINI, 2009, p. 222).

Desse modo, podemos dizer que a TASHC é o campo de estudo em que são observadas as atividades que os indivíduos realizam a fim de colaborar com a interação em contextos culturais diversos, "a partir do alcance dos objetivos determinados pela coletividade, e também a fim de satisfazer necessidades individuais, desde que estas possuam alguma relação com as necessidades do grupo" (LARRÉ, 2014, p. 81). Por esse viés, o ser humano relaciona-se com o mundo ao seu redor e com a coletividade em que se encontra e "vai 'construindo-se', como indivíduo interativo, o seu conhecimento através de uma interação mediada por diversas relações intra e interpessoais" (SCHETTINI, 2009, p. 226), incluindo-se aí educador e aprendiz. 


\section{As Atividades Sociais como práticas transformadoras do educador e do aprendiz}

Ao pensarmos no ensino-aprendizagem de LI na modalidade a distância, podemos tomar como base a visão de linguagem da TASHC, sócio-histórico-cultural por natureza, e as a serem propostas no AVEA, no sentido de proporcionar aos aprendizes um objeto compartilhado (ENGESTRÖM, 1999) através do qual se possa chegar ao resultado de aprendizagem efetiva de aspectos da LI, dentro de um contexto que seja relevante para os aprendizes em questão. Essa concepção se torna viável especialmente quando a AS proposta é correlata ao campo de aprendizagem em que o aprendiz está se formando.

O conceito de atividade humana (ENGESTRÖM, 1999) nos traz uma visão mais estruturada no que tange ao seu sistema. Para o autor, a atividade é um sistema complexo que pode ser analisado dentro das relações da seguinte estrutura:

FIGURA 1 - O sistema de atividade humana proposto por Engeström (1999)

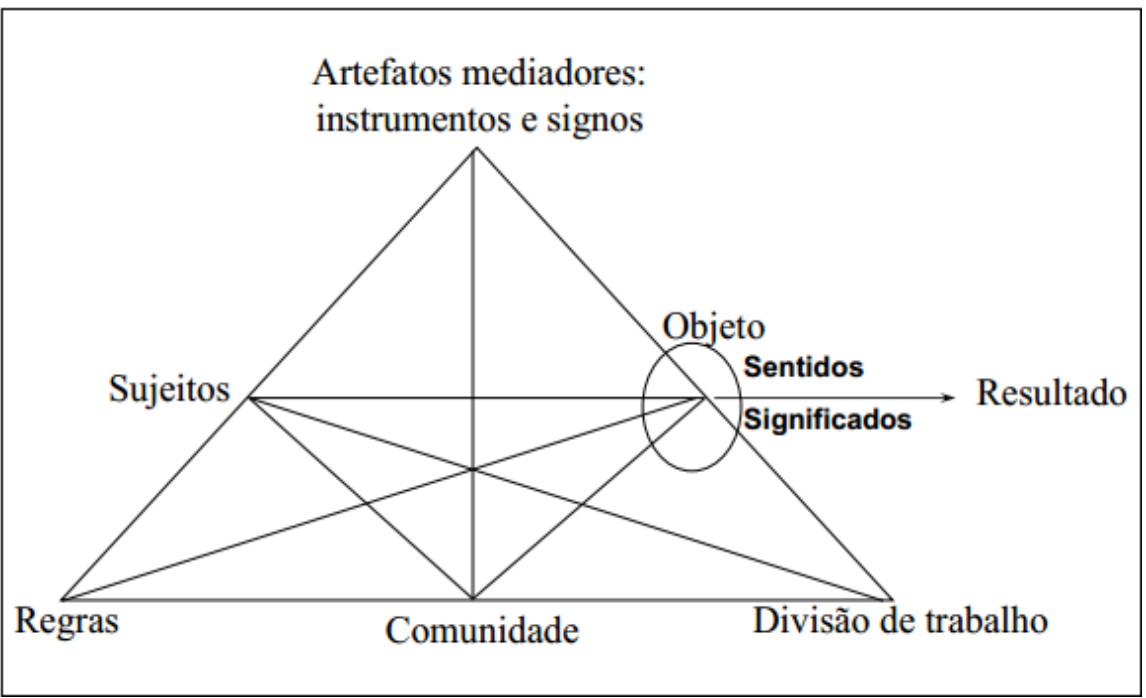

Em Larré (2014) detalhamos o sistema apresentado na Figura 1: 
[...] o sujeito se refere ao campo do individual: é o indivíduo que age em relação ao motivo-objeto, realizando a atividade. O objeto é aquilo para o que o sujeito direciona sua atividade, sendo o que é idealizado, desejado pelo sujeito; ele é moldado e transformado em resultado, "com a ajuda do físico e do simbólico, dos instrumentos de mediação externos e internos, incluindo tanto ferramentas como signos" (CEDRO; MOURA, 2012, p. 47). A comunidade é formada por aqueles indivíduos que compartilham o objeto da atividade. As regras são as regulamentações explícitas e implícitas que limitam as ações dentro da atividade. A divisão do trabalho é formada pelas tarefas, funções dos sujeitos que formam a comunidade e que visam ao alcance do objeto geral; geralmente ela é hierarquizada entre os membros de tal comunidade. Os instrumentos - também chamados de artefatos ou ferramentas - são "meios de modificar a natureza para alcançar o objeto idealizado, revelam a decisão tomada pelo sujeito" (LIBERALI, 2012, p. 24) e são usados para um fim predefinido (instrumento-para-resultado) ou construído durante o processo da atividade (instrumento-e-resultado) (LARRÉ, 2014, p. 80).

Ao considerarmos o ensino de língua por meio de AS, estruturamos a matriz curricular ou as expectativas de aprendizagem a partir das "esferas em que os sujeitos circulam e dos anseios de participação social que têm" (LIBERALI, 2012, p. 23). Dessa maneira, por estar atuando em um contexto mediado por uma língua diferente da sua língua materna, o aprendiz identifica relevância nas atividades propostas em sala de aula e consegue ao mesmo tempo se considerar como um cidadão do mundo, pois as AS possibilitam a criação de contextos de intervenção na vida.

Pensando que tal AS é composta por diversos gêneros que concretizam as possibilidades de atuação na esfera selecionada, sendo esses gêneros considerados artefatos/instrumentos, selecionamos para o planejamento e implementação do curso alguns gêneros focais (Resumo para inscrição em evento; Pôster científico em inglês) e gêneros orbitais (Website de inscrição do evento; gravação de áudio; wikis; questionários como atividades; fóruns de discussão; recurso "tarefa" do Moodle; vídeos), de modo que os aprendizes conseguissem de fato observar na prática como ocorre o "sistema ${ }^{2}$ responsável pela formação, transformação e manutenção dessa atividade” (LIBERALI, 2012, p. 24).

\footnotetext{
${ }^{2}$ De acordo com Bazerman (1994) apud Liberali (2012, p. 24), o sistema de gêneros se trata de "gêneros inter-relacionados que interagem uns com os outros em determinado contexto".
} 
Nesse sentido, os sujeitos envolvidos em uma AS se mantêm dirigidos a um objetivo determinado para atender a uma necessidade específica. Isso significa que uma AS proposta como forma de aprender uma LE é uma atividade realizada como maneira de satisfazer as necessidades de aprendizagem da língua-alvo com determinado fim específico; mas também uma proposta de atuação coletiva dos sujeitos para que estes alcancem aquele objeto compartilhado e satisfaçam suas necessidades particulares, mesmo que de modo parcial, intervindo no microcosmos onde estão inseridos por meio do trabalho escolar.

Com relação ao planejamento do curso, citamos Almeida Filho (2012), que afirma haver duas situações em que se pode realizar um planejamento de curso de línguas: a) "em situações de ensino de línguas onde já existem planejamentos considerados inadequados em alguma medida" (ALMEIDA FILHO, 2012, p. 35); ou b) em situações novas que requerem a implementação de um processo de ensino-aprendizagem.

No contexto do curso supramencionado, o planejamento se deu como uma nova situação de ensino-aprendizagem a partir das necessidades observadas no contexto do PPGTEG, e teve como finalidade contribuir tanto para o programa de pós-graduação em si quanto para os aprendizes que estavam prestes a ter um evento científico de sua área e não queriam perder a oportunidade de participação no mesmo, como havia acontecido no ano anterior.

\section{Considerações metodológicas}

Esta pesquisa pode ser caracterizada como pertencente à linha metodológica da pesquisa-ação, na qual o professor-pesquisador realiza intervenções em um dado contexto de modo que possa estabelecer uma relação de cooperação entre todos os participantes da pesquisa a fim de compreender e aprimorar suas práticas e transmitir o conhecimento adquirido a outros pesquisadores e praticantes, dentro de uma abordagem problematizadora da prática docente. A tentativa aqui é a de contribuir, com a pesquisa realizada e historicamente determinada, para avanços no planejamento de cursos de LI na EaD, nos materiais didáticos e na produção de conteúdos no referido contexto, colaborando com um fazer docente mais aperfeiçoado que tenha como meta uma educação de qualidade. "Nessa perspectiva, a pesquisa ocorre ao mesmo tempo em que se ensina" (LIMA; MARTINS, 2006, p. 51). 
Na pesquisa-ação, "o pesquisador exerce uma importante função, desencadeando ações no grupo que permitem a solução do problema, objetivando aumentar o seu conhecimento e o grau de consciência do grupo envolvido" (LIBERALI; LIBERALI, 2011, p. 25). Sobre esse mesmo assunto, Paulo Freire nos diz que

O que há de pesquisador no professor não é uma qualidade ou uma forma de ser ou de atuar que se acrescente à de ensinar. Faz parte da natureza prática do docente a indagação, a busca, a pesquisa, o de que se precisa é que, em sua formação permanente, o professor se perceba e se assuma, porque professor, como pesquisador (FREIRE, 1996, p. 32).

Esse olhar epistemológico, que Freire (1996) confirma como devendo ser inerente ao professor, é o que norteia nossa escolha para a pesquisa aqui relatada.

Esse tipo de pesquisa é, por consequência, de caráter qualitativo, que reflete um trabalho que se preocupa com a interferência na realidade social e "com o universo dos significados, dos motivos, das aspirações, das crenças, dos valores e das atitudes que não podem ser reduzidos à operacionalização de variáveis" (LIBERALI; LIBERALI, 2011, p. 21). Por ser pautado na interpretação, o método qualitativo, segundo os mesmos autores, propõe "perceber a realidade a partir dos significados" (LIBERALI; LIBERALI, 2011, p. 21) e a partir dos sentidos que os participantes da pesquisa atribuem à realidade específica de interesse do pesquisador.

\subsection{Contexto de pesquisa}

O contexto de pesquisa é o curso de mestrado do Programa de Pósgraduação em Tecnologia e Gestão em Educação a Distância (PPGTEG) da Universidade Federal Rural de Pernambuco (UFRPE). A turma 2017.1, composta por 30 alunos e professora-pesquisadora, realizou as atividades que aqui serão descritas e analisadas numa carga horária de 30 horas-aula (referentes às disciplinas de Seminários I e II).

Uma observação a ser feita é que este programa de mestrado possui quatro disciplinas de 15 horas-aula denominadas "Seminário" que vão de I a IV. O objetivo de tais disciplinas é integrar à grade curricular cursos de curta duração de professores que possam colaborar com o mestrado, podendo então serem convidados profissionais que estejam de passagem no país, ou 
até mesmo professores "da casa" que tragam um tipo de contribuição com temática transversal aos conteúdos previstos pelo curso, mas que façam sentido com o intuito do programa, enriquecendo, assim, a formação do aluno.

Ao conversar com a direção do departamento de EaD da UFRPE e também com o coordenador do PPGTEG, nos foi relatado um acontecimento de 2016 que os fez repensar sobre como o curso de mestrado poderia incorporar aulas de inglês. Em termos mais informais, podemos dizer que conseguimos unir o útil ao agradável. Relataremos aqui brevemente: no ano de 2016, os alunos dos PPGTEG foram contemplados com a oportunidade de apresentar seus projetos de pesquisa em um evento internacional promovido pelo European Multidisciplinary Research Network on the Challenges and Uses of Information and Communication Technologies (EUTIC), naquele ano realizado na Grécia. A grande problemática enfrentada pelo departamento e programa de pós-graduação foi exatamente a dificuldade do idioma estrangeiro no qual alunos e professores orientadores deveriam apresentar seus trabalhos. O evento permitia apresentações em francês ou inglês; no entanto, nenhum dos alunos possuía formação e/ou orientação suficientes nas referidas línguas.

Isso ocasionou na perda de oportunidades relacionadas ao convite da instituição estrangeira para que todos os alunos do PPGTEG pudessem apresentar seus trabalhos e, consequentemente, divulgar as pesquisas do Nordeste do Brasil em todas as linhas aceitas pelo evento de 2016, a saber: Engajamento, eco-cidadania e desenvolvimento sustentável; Redes de turismo e novas mídias; Evoluções societárias e inteligência coletiva; Democratização de espaços de expressão, mídia e redes sociais; TIC e engajamento público/político; Sistemas de informação e mudanças no papel da experiência do usuário, crowdsourcing; Novas formas de governança, experiência do usuário e ergonomia; Troca e transferência de conhecimento, e-learning, publicação eletrônica, $\mathrm{MOOCs}^{3}$; Redes e videogames, jogos sérios; Internet das coisas, realidade aumentada, humanos aumentados; Outsourcing, computação em nuvem; Abertura de espaços de informação, dados abertos, arquivos abertos; Debates TIC, interculturais e políticos; Eficácia da ação pública, nova administração pública, governo aberto.

\footnotetext{
${ }^{3}$ MOOC (Massive Open Online Course), ou, em língua portuguesa Curso Online Aberto e Massivo, consiste em um curso aberto que visa atender um grande número de alunos, através do uso de ambientes virtuais de aprendizagem.
} 
Como no programa havia a flexibilidade das disciplinas de Seminários, cada qual com 15h/aula, nesse levantamento de necessidades realizado junto à direção da Unidade Acadêmica de Educação a Distância (UAEAD) da qual o PPGTEG faz parte, vimos um ambiente em que a implementação de um curso com as características sobre as quais falamos anteriormente seria de grande utilidade.

Almeida Filho (2012, p. 39) nos fala sobre o fato de que a primeira fase do planejamento sistemático de um curso de línguas é "o estudo e caracterização do contexto ou situação de planejamento culminando com a definição dos objetivos do curso". Desse modo, tal contexto de necessidade real foi o grande norteador do planejamento inicial do curso, que seria a distância, primeiramente pelo fato de que grande parte da turma reside no estado do Maranhão, e, segundo, porque gostaríamos de aliar a nossa pesquisa a essa modalidade.

Como também é fundamental para o planejamento (ALMEIDA FILHO, 2012; LIBERALI, 2012), buscamos dados sobre os alunos, o curso, a cultura de aprender dos alunos e do PPGTEG por meio de conversas com pessoas familiarizadas com a situação, como o coordenador do PPGTEG e a professora do programa e também diretora da UAEAD onde o PPGTEG se encontra.

\subsection{Participantes da pesquisa}

Os participantes dessa pesquisa foram alunos do Programa de Mestrado Profissional em Tecnologia e Gestão da Educação a Distância (PPGTEG) da UFRPE. Em sua grande maioria, esses alunos já exerciam, quando da coleta de dados, atividades docentes em cenários variados de ensino da educação superior. Todos os sujeitos são maiores de 18 anos e compunham uma sala heterogênea composta de indivíduos dos sexos feminino e masculino. Optei, aqui, por não utilizar os nomes reais dos indivíduos participantes.

\subsection{Instrumentos e procedimentos de produção e coleta de dados}

Como procedimento de construção de dados, planejamos o curso de "Seminários: apresentação de pôster em inglês" mediante o levantamento de necessidades baseadas no que "o aluno precisará para agir no mundo real" 
(BARBIRATO, 2016, p. 125) e no que o programa de pós-graduação no qual a pesquisa ocorreu gostaria de desenvolver com os aprendizes.

Dividimos o curso em Weeks que correspondem a unidades referentes aos gêneros orbitais e focais a serem trabalhados para o alcance do objeto definido pela professora-pesquisadora, juntamente com a coordenação de curso, e almejado pelo grupo, que foi o desenvolvimento das habilidades necessárias para apresentar o pôster em língua inglesa no EUTIC $2017^{4}$.

A coleta se deu por meio dos dados gerados na plataforma Moodle institucional, dos registros das aulas criadas, das interações dos alunos, professora-pesquisadora conteudista e professora-tutora, dos relatórios gerados pelo AVA e também aplicamos, como mencionado anteriormente, um questionário avaliativo ao final da disciplina, na aula presencial ministrada, e uma entrevista semiestruturada com alguns dos participantes.

A seguir, elenco um quadro resumitivo das Weeks criadas com suas respectivas datas de upload na plataforma, junto com uma breve descrição do que foi desenvolvido:

\begin{tabular}{|l|l|l|}
\hline \multicolumn{1}{|c|}{ Week } & \multicolumn{1}{|c|}{ Data } & \multicolumn{1}{c|}{ Objetivo } \\
\hline $\begin{array}{l}\text { Week 1 - Presenting our } \\
\text { course + Academic Genres }\end{array}$ & $\begin{array}{l}24 \text { a } 30 \text { de } \\
\text { abril de } 2017\end{array}$ & $\begin{array}{l}\text { Apresentar o curso brevemente, acolher } \\
\text { e tirar dúvidas iniciais. } \\
\text { Levantar o conhecimento prévio dos } \\
\text { alunos quanto ao gênero resumo com } \\
\text { atividade de leitura. }\end{array}$ \\
\hline $\begin{array}{l}\text { Week 2- Understanding } \\
\text { the event's website }\end{array}$ & $\begin{array}{l}1 \text { a } 7 \text { de maio } \\
\text { de } 2017\end{array}$ & $\begin{array}{l}\text { Compreender as especificidades de uma } \\
\text { webpage de evento científico. }\end{array}$ \\
\hline $\begin{array}{l}\text { Week 3- The abstract in } \\
\text { details }\end{array}$ & $\begin{array}{l}9 \text { a } 16 \text { de maio } \\
\text { de } 2017\end{array}$ & $\begin{array}{l}\text { Analisar comparativamente dois abstracts } \\
\text { submetidos a edições anteriores do } \\
\text { mesmo evento para o qual os alunos } \\
\text { estão se preparando. }\end{array}$ \\
\hline $\begin{array}{l}\text { Week 4 - Organizing } \\
\text { submission (EUTIC Recife } \\
\text { 2017) }\end{array}$ & $\begin{array}{l}17 \text { a } 24 \text { de } \\
\text { maio de } 2017\end{array}$ & $\begin{array}{l}\text { Produzir, revisar e reescrever, } \\
\text { juntamente com momentos de } \\
\text { colaboração entre os alunos do grupo, } \\
\text { os abstracts para o evento. }\end{array}$ \\
\hline
\end{tabular}

\footnotetext{
${ }^{4} \mathrm{O}$ Eutic (Rede Internacional e Interdisciplinar para os Desafios e Usos das Tecnologias da Informação e Comunicação) Recife ocorreu no período de 18 a 20 de outubro de 2017. Mais informações disponíveis em: <https://bit.ly/2ItCo63>.
} 


\begin{tabular}{|l|l|l|}
\hline $\begin{array}{l}\text { Week 5 - Introductions to } \\
\text { the academic poster }\end{array}$ & $\begin{array}{l}31 \text { de maio a } \\
7 \text { de junho de } \\
2017\end{array}$ & Trabalhar com pôsteres científicos. \\
\hline $\begin{array}{l}\text { Week 6-Preparing for the } \\
\text { oral presentation }\end{array}$ & $\begin{array}{l}8 \text { a } 27 \text { de } \\
\text { junho de } 2017\end{array}$ & $\begin{array}{l}\text { Analisar uma apresentação de pôster } \\
\text { através de vídeo e discutir com colegas } \\
\text { para as análises. }\end{array}$ \\
\hline $\begin{array}{l}\text { Week 7-Preparing the } \\
\text { content of yourposter }\end{array}$ & $\begin{array}{l}28 \text { de junho a } \\
2017\end{array}$ & $\begin{array}{l}\text { Escrever individualmente partes } \\
\text { específicas do pôster de cada } \\
\text { participante. }\end{array}$ \\
\hline Aula presencial & $\begin{array}{l}14 \text { de julho de } \\
2017\end{array}$ & $\begin{array}{l}\text { Analisar e reescrever os conteúdos para } \\
\text { os pôsteres postados no AVEA. Praticar } \\
\text { oralmente a apresentação de pôster } \\
\text { (performance controlada) do script } \\
\text { realizado. }\end{array}$ \\
\hline Week 8 - Posting your \\
voice recordings
\end{tabular}

Fonte: elaborado pela autora.

\section{Análise do impacto do curso planejado e implementado pela fala dos participantes}

Já que nosso objeto de pesquisa foi o planejamento em si, avaliaremos nesse ponto de nosso texto três aspectos fundamentais para a análise do desenvolvimento dos participantes do curso quanto às atividades propostas no curso de inglês: as dificuldades e a desenvoltura dos aprendizes quanto ao curso planejado, a qualidade da participação deles e, por fim, mas não menos importante, a percepção dos aprendizes sobre o curso planejado e implementado. Para tanto, nos apoiaremos nos resultados obtidos por meio dos instrumentos de pesquisa: questionário e entrevista semiestruturada realizados com os aprendizes e também as atividades realizadas por eles na plataforma virtual.

\subsection{Desenvoltura e dificuldades dos alunos com as atividades propostas no curso}

É importante mencionar que, por meio da voz dos participantes do curso, tivemos acesso a suas dificuldades e desenvoltura em geral no 
AVEA. Para isso, as respostas ${ }^{5}$ para as perguntas 2 (Which activities did you like the most and which ones you did not? Why?) e 3 (What have you learned about poster presentation during the classes that you did not know before?) do questionário final são importantes.

Nas respostas da pergunta 2 verificamos que alguns dos alunos alegaram ter sentido dificuldade nas atividades pela exigência (a partir da Week 2) de todas serem respondidas na língua-alvo:

\section{"I didn't answer all the activities, I had much difficulty." (Wilson)}

"Só fiz até a atividade 4. Tenho muita dificuldade com inglês." (Fabi)

“Todas acrescentou muito muito. Não tive dificuldade em realizá-las exceto a week 5 que foi a apresentação do poster numa conferência. Porque foi toda em inglês." (Rosie)

Apesar de esses alunos terem produzido os textos e respondido às atividades em língua inglesa, alegam dificuldade em se expressar na mesma, demonstrando que ainda possuem certa insegurança para realizar autoavaliações que não contenham influência forte do filtro emocional e de uma postura fortemente crítica quanto à própria performance. Essa autocrítica negativa em processos de avaliação com alunos de LE em ambiente on-line é bastante comum, como constata Cavalari (2011). A autora diz que quando um aprendiz define seus parâmetros de avaliação do próprio desempenho, é comum que haja a consideração de parâmetros altos dependendo dos objetivos do aprendiz a longo prazo, justificando a atitude crítica e alto nível de exigência. Para obtermos mais dados sobre a razão dos parâmetros utilizados pelos alunos Wilson, Fabi e Rosie, seria indicado realizar mais coleta de dados como entrevistas, por exemplo.

Nas respostas para a mesma pergunta, também é possível perceber que a maior dificuldade dos alunos foi relacionada ao cumprimento adequado das wikis propostas. Segundo os aprendizes, que mencionaram palavras como "confusa" e "desafiadora" para a atividade com a ferramenta, os motivos foram relacionados aos seguintes fatores:

\footnotetext{
${ }^{5}$ Todas as respostas dos participantes estão conforme seu registro na plataforma. Portanto, o leitor verificará deslizes de ordem ortográfica e gramatical que não impedem, no entanto, a compreensão do texto como um todo.
} 
a. o próprio grupo não ter estabelecido parâmetros internos para que houvesse colaboração de fato: "... the students did not establish a standard to build the collaboration" (Aline);

b. falta de familiaridade com a ferramenta: "I did not adapt very much to the wiki, perhaps for the ignorance of its proposals" (Michael); "... acho que os alunos devem receber uma aula antes pois muitos alunos ao invés de editar e acrescentar, eles apagavam toda a wiki" (Irla);

c. falta de familiaridade com a atividade de cunho colaborativo em grandes grupos: "I think it was difficult to work in group" (Joana); "Também foi difícil a atividade no wiki, turma muito grande para esse tipo de atividade" (Wilma).

Emídio (2017, p. 159) aponta a necessidade de que a mentalidade dos alunos mude no trabalho com a wiki, pois eles "devem se engajar mais em um trabalho colaborativo e menos em um trabalho cooperativo". Como o uso da ferramenta não garante que esse trabalho colaborativo ocorra, é necessário que parta do professor a conscientização sobre a importância do trabalho de cunho colaborativo, para que os problemas encontrados em trabalhos em grupo do ambiente presencial não sejam transpostos para o ambiente virtual (EMÍDIO, 2017).

No entanto, a wiki não foi objeto somente de críticas. Os aprendizes também a mencionaram como uma atividade da qual gostaram: "The wiki was also very good..." (Aline); "The activities I liked the most were Week. 5, the Wiki on 'Dos and don'ts for a scientific poster', in which I was able to know more about the specificities of the type of scientific production studied..." (Jorge).

Já os relatos ligados às atividades que os participantes mais gostaram no curso evidenciaram aspectos muito importantes que comprovam o quanto o planejamento teve pontos fortes para o objetivo a que foi destinado:

a. os fóruns de interação: "Sim, gostei mais da participação nos fóruns de dúvida, onde pude avaliar o meu nível de conhecimento da língua inglesa" (Gerald); Michael também relata sua satisfação quanto à proposta de uso da ferramenta, como é possível ver mais adiante. Somente duas alunas (Chris e Mara) mencionam que não conseguiram se atualizar quanto às discussões do fórum semanal por falta de tempo;

b. os vídeos produzidos pela professora-pesquisadora: "Gostei das atividades que envolvia videoaulas, e também da indicação dos links para complemento, principalmente com linguagem visual clean” (Liz); 
"Eu gostei bastante do vídeo, da gravação do vídeo, é algo novo que importa a gente" (Mateus);

c. clareza das instruções: "I liked the lessons of all the classes. Were explained well' (João Victor);

d. diversas maneiras de contato com os aprendizes: "Não fiz todas as aulas, mas percebi nos poucos acessos formas de chamamento para a participação como os vídeos, o Facebook, os fóruns" (Selma); “Aprendi que o aluno pode ser acompanhado em uma sala de aula virtual mesmo de longe o professor pode desenvolver uma boa interação com o aluno." (Natália);

e. atividade de análise do vídeo da Week 6: “... and the Week 6, when we analyzed the video about the tips at the poster presentation" (Jorge); "The most activity that I like it was six, I liked to watch the video and answer the question, so in that exercise I could see that it is possible to understand something in English yet" (Joana); "I was very enthusiastic about the proposed questions (quiv), because it contributes in an effective way to understanding of the content. I say the same as participating in the forums" (Michael);

f. atividades de produção textual relacionadas aos gêneros focais (abstract e poster): "The abstract was excellent for the challeng and also for having learned about it" (Aline); "O resumo do poster, o layout, a atividade 5, 6 e 7" (Samuel); "Do resumo do poster e da atividade 7. Fiz todas." (Lucy); "Gostei das atividades da primeira e quarta semana." (Marina); "Gostei mais das atividades de produção do poster" (Tiago); "I liked the first one up to the fourth activity" (Mara); "A construção do abstract foi o que gostei mais" (Wilson); "Gostei mais dos que foram trabalhados com a produção do artigo. As orientações e as que qualificavam o trabalho" (Felipe).

A partir dos resultados das respostas à pergunta 2 do questionário aplicado aos alunos, é possível perceber que mesmo tendo havido atividades, como a wiki, que foram consideradas como complexas, os participantes do curso conseguiram estabelecer uma ligação afetiva com determinadas atividades por perceberem seu próprio progresso no decorrer da escrita, de feedbacks da professora-pesquisadora e da professora-tutora e da reescrita. Uma das vantagens que podemos perceber no uso da plataforma virtual para ensino de LI por meio de AS é que, devido à maior disponibilidade de material de consulta na internet, os alunos podem se sentir mais aptos 
para fazer suas produções escritas. Isso traz uma maior segurança para o desenvolvimento dessa habilidade e, consequentemente, uma preferência, por exemplo, quanto às atividades de produção (como a do ponto mencionado).

\subsection{Qualidade da participação dos aprendizes no curso planejado}

Nesta seção iremos falar de como os aprendizes participaram das atividades em geral. A nota final do curso, exigência da instituição e do PPGTEG, foi composta por uma média de duas avaliações parciais (chamadas de verificação de aprendizagem). Portanto, a avaliação foi calculada pela média aritmética das seguintes notas: a) nota $1-60 \%$ participação de fóruns e atividades em geral, 40\% abstract da $W e e k$; b) nota 2 - 60\% participação de fóruns e atividades em geral, 40\% conteúdo do poster da Week 7.

Como forma de analisar a qualidade da participação dos aprendizes no curso de LI por meio da AS “apresentar pôster científico em evento internacional", utilizarei dos dados coletados através de três instrumentos, especificamente: a) os dados obtidos no AVEA pela observação de atividades completas pelos alunos; b) as respostas dos aprendizes às perguntas 3 (What have you learned about poster presentation during the classes that you did not know before?) e 5 (Have you submitted your work to EUTIC 2017? Why/why not?) do questionário final, pois, já que o objeto da AS seria a participação deles na AS proposta, cremos que este aspecto deve ser avaliado; e c) a participação dos aprendizes nos fóruns em geral.

Iniciando pela verificação dos relatórios gerado pelo AVEA de atividades completas pelos participantes do curso, é possível verificar os seguintes dados: 


\begin{tabular}{|c|c|c|}
\hline Módulo do curso & Tipo de atividade & $\begin{array}{c}\text { Número de alunos } \\
\text { que participaram }\end{array}$ \\
\hline Week 1 & Reading activity (abstract) & 22 \\
\hline Week 2 & Questions about "Call for papers" file & 24 \\
\hline Week 4 & Your abstract for EUTIC & 25 \\
\hline Week 6 & Questionnaire about the video & 13 \\
\hline Week 7 & Writing the parts of yourposter & 21 \\
\hline Week8 & Posting your voice recordings & 18 \\
\hline
\end{tabular}

É perceptivel que a atividade que mais houve participação dos aprendizes foi a da escrita e postagem do abstract. Fazendo uma triangulação desse dado em específico com os relatos dos alunos, sugere-se que a maioria deles realizou as atividades entre as $W e e k, 1$ e 4 , por terem gostado de tais atividades, mas também porque relataram "falta de tempo" para a realização das atividades subsequentes. Sabemos que os participantes do curso trabalhavam no ambiente acadêmico, em sua maioria em uma faculdade particular do Maranhão, como professores ou trabalhadores do setor administrativo. A Week 5 até o último módulo aconteceram em uma época do ano (entre abril e julho) que tipicamente há a fase de provas nos ambientes escolares, aumentando, consequentemente, a carga de trabalho dos funcionários da instituição. Isso pode justificar, em específico, os depoimentos abaixo:

"Não foi possível realizar a 6 e 7 porque não tive tempo suficiente." (Mariana)

“... tive pouco tempo para responder." (Liz)

"No, because of other activities of work." (João Victor)

Isso acarretou também uma diminuição de sua atuação nas atividades finais. No entanto, consideramos a participação dos aprendizes como excelente, já que, dos trinta participantes, pudemos registrar que houve 68,3\% de participação ativa dos alunos nas atividades principais do curso.

Quanto à participação dos alunos de modo geral nos fóruns, contabilizamos somente as entradas feitas pelos aprendizes, sem considerar as entradas da professora-pesquisadora e da professora-tutora (a qual participou somente do fórum da Week 4). Veja o quadro descritivo a seguir: 


\begin{tabular}{|c|c|c|}
\hline Módulo & Tipo de fórum & $\begin{array}{c}\text { Número de entradas dos } \\
\text { alunos participantes }\end{array}$ \\
\hline Week 1 & Tira-dúvidas & 7 \\
\hline Week 2 & Tira-dúvidas & 22 \\
\hline Week 3 & Tira-dúvidas & 16 \\
\hline Week 3 & Interação para execução de atividade & 85 \\
\hline Week 4 & Tira-dúvidas & 66 \\
\hline Week 5 & Tira-dúvidas + interação para & 48 \\
\hline Week 6 & execução de atividade & 21 \\
\hline Week 7 & Relato de experiência & 14 \\
\hline Week 8 & Tira-dúvidas & 16 \\
\hline
\end{tabular}

Nos módulos das Weeks 3, 4 e 5 é possível perceber um recrudescimento considerável do número de entradas dos participantes do curso. Por conta das atividades da wiki, que ocorreram nas semanas 3 e 5, os alunos estabeleceram uma grande participação nos fóruns, pois para a realização da atividade colaborativa eles deveriam interagir por esta ferramenta. $\mathrm{Na}$ Week 4 , a atuação dos aprendizes foi alta devido ao fato de que naquela semana eles deveriam entregar suas primeiras versões do abstract para o EUTIC, atividade esta que gerou bastante insegurança e dúvidas dos alunos, sempre sanadas pelas professoras pesquisadora e tutora.

Quanto às respostas dos alunos à pergunta 3 (What have you learned about poster presentation during the classes that you did not know before?) do questionário final, temos depoimentos que expressam em sua maioria o fato de antes do curso não conhecerem bem o gênero e terem aprendido sobre aspectos enunciativos, linguísticos e discursivos relacionadas à AS proposta, bem como é possível perceber na categorização que fizemos de alguns exemplos dos relatos:

- alunos que afirmaram não conhecer o gênero pôster científico antes do curso:

"Pretty much everything! I did not know about this mode of scientific work." (Jorge) "Não conhecia nada sobre o assunto, então aprendi tudo com a professora Julia." (Irla)

"I really did not know, as it was something new, it was quite challenging." (Chris)

"I learned everything as I said, I never submitted any work before." (Joana) 
"Praticamente tudo, o poster é uma ferramenta que organiza as ideias para uma apresentação científica, adequada na divulgação de pesquisas. Aprendi também a forma correta de apresentar para os participantes." (Liz)

- alunos que afirmaram ter aprendido questões referentes aos aspectos enunciativos, linguísticos e discursivos do gênero:

"Aprendi que é uma apresentação simples e prática." (Samuel) "As etapas para a preparação e apresentação do poster." (Rosie)

"Aprendi várias coisas como construir um poster e o que eu não sabia era sobre o tempo de apresentação que seria só dois minutos." (Marina) "That poster is an excellent resource and quite effective." (Mara) "The steps of the preparing and submitting the work to the institution." (Michael)

- alunos que mencionaram a metodologia do curso:

"A metodologia de construção foi muito interessante." (João)

"I learned to make a correct poster. Perhaps, English course, in a strange path, helped me a lot. The literature disponible mostly is in English. The gold standard at least in world wide." (Francisco)

"Basicamente todas as atividades são novas para mim em inglês, mas uma atividade bem diferente foi responder o questionário a partir do vídeo em inglês." (Wilson)

- alunos que já conheciam o gênero e aprofundaram o conhecimento com o curso:

"Acredito que já conhecia todas as dicas por já ter apresentado poster em evento, mas foi muito bom para saber que estou no caminho certo nas apresentações." (Betty)

"It was profitable enough. I could perfect what I understood about posters." (João Victor)

Quanto a algumas das adjetivações estabelecidas pelos alunos em relação ao gênero focal aprofundado para a performance na AS, podemos ver expressões como: "significant" (Wilson), "apresentação simples e prática" (Samuel e Lucy), "excellent resource", "quite effective" (Mara), estando, pois, de acordo com as características desse gênero, objetivo por natureza. 
As respostas para a pergunta 5 (Have you submitted your work to EUTIC 2017? Why/why not?) nos foram fornecidas na aula presencial, conforme mencionamos na seção da Metodologia deste trabalho.

As respostas afirmativas mencionaram questões que giram em torno das possibilidades abertas pelo ensino-aprendizagem por meio de AS, que são:

- "Brincar de ser" para vir a ser: "Yes, for the possibility of attending an international event and the support given by the teacher" (Aline); "Sim, já submeti meu trabalho. Acredito que a aprendizagem só se torna significativa vivenciando experiências acadêmicas constantes" (Gerald).

- Empoderamento da voz do aluno quanto ao seu papel desempenhado na AS, em nosso caso experienciado, o papel de pesquisador: "Yes, because I intend to improve my knowledge and skills around this practice of great relevance to the researcher's personal life" (Michael); "Sim. Participar de um congresso internacional; enriquecer meu currículo acadêmico" (Irla); "Yes, I submitted. I was interested in knowing and presenting at an international event both for the great experience gaines, as well as for teh curricular increase" (Jorge).

Verificamos que $48 \%$ dos alunos que responderam ao questionamento não haviam enviado seus abstracts para o evento por motivos como:

- Preço da inscrição no evento:

"I did not submit my work to EUTIC 2017 because it will be very expensive for me." (Wilson)

"No, it's very expensive. We are living a very unstable moment in our economy and of course that situation harms common people like me." (Francisco)

- Insegurança quanto ao uso da língua-alvo:

"Não vou me submeter por não ter a segurança necessária para a apresentação." (Samuel)

"Infelizmente não porque não tenho domínio do inglês. Estou fazendo um curso para no próximo ter condição de submeter um trabalho." (Rosie)

"Não, pois não tenho domínio do inglês." (Natália) 
"Não, por falta de segurança quanto ao idioma." (Carla)

"Não, tenho muita dificuldade e não sinto segurança em apresentar nesse intervalo de tempo até outubro. Receio não adquirir habilidade suficiente até esse período." (Liz)

- Falta de orientador em sua pesquisa, não início do projeto ou de tempo para submissão:

"Não. No período de envio ainda estaria sem orientador, sendo assim senti-me insegura." (Marina)

"Não, falta de tempo." (Tiago)

"Não, minha pesquisa ainda não foi iniciada." (Wilson)

"Não, pois não fiz o projeto.” (Rafael)

"No, because of other activities of work." (João Victor)

É importante dizer que alguns dos relatos que mencionam a não submissão dos abstracts ao EUTIC foram alterados ao final do encontro quando estes alunos decidiram enviar seu trabalho para o evento. Em conversas pessoais, esses alunos justificaram sua mudança por terem acreditado que estavam menos inseguros quanto à performance na AS. Relatamos aqui o exemplo de dois alunos que no questionário nos dizem não terem se inscrito pelas seguintes razões: "falta de tempo" (Tiago) e "expensive" (Francisco). No entanto, estes mesmos aprendizes em entrevista semiestruturada realizada cerca de dois meses após o término do curso, nos respondem à pergunta "Você se inscreveu no EUTIC com o resumo escrito em inglês durante nossa disciplina? Por quê?’":

"Sim, me inscrevi no EUTIC com o resumo em inglês durante nossa disciplina, porque fiquei estimulado e desafiado a fazê-lo em língua estrangeira. $\mathrm{O}$ modo como a disciplina se deu, deixou-me motivado para tal." (Francisco)

"Sim. Porque tinha interesse em participar do evento tendo em vista que seria uma oportunidade para exercitar o idioma bem como divulgar meu trabalho." (Tiago)

Essa mudança de perspectiva nos é muito importante, pois, devido ao curso ter sido realizado a partir da preparação para uma AS, tendo em vista seu objeto-motivo (LARRÉ, 2014)a, os alunos percebem que 
conhecer é uma nova forma de poder e que "permite desejar alcançar novas possibilidades, novos horizontes” (LIBERALI, 2012, p. 33). Concordamos nesse sentido com a autora quanto a este movimento percebido em nossa experiência aqui apresentada que nos diz que "Trabalhar com Atividades Sociais seria, portanto, partir do universo imediato da vida vivida para imaginar possibilidades futuras" (LIBERALI, 2012, p. 33).

\subsection{Percepções dos aprendizes sobre o curso planejado}

Quanto às percepções dos aprendizes sobre o curso, utilizaremos os dados coletados pela entrevista semiestruturada e respostas às perguntas 1 , 4, 6 e 7 do questionário final.

Obtivemos respostas para a pergunta 1 do questionário (What can you say about the classes for presenting a poster in English at PPGTEG?) com 100\% de relatos positivos para as aulas ministradas no AVEA, nos quais apresentaram valorações como: very interesting, an excellent experience, aulas bem direcionadas, criativas, boa proposta, disciplina proveitosa, focada, bem estruturada, com boa interação professora-alunos, entre outras. Todas elas se referindo ao fato de que o curso os preparou para o evento, ou seja, para a escolha de planejar o curso na AS "apresentar pôster científico em evento internacional", mesmo sem que a professora-pesquisadora houvesse mencionado explicitamente as concepções da TASHC. Abaixo, apresentamos algumas das respostas:

"It's very interesting, because it prepares the student for participating in the event." (Wilson)

"It was an excellent experience, where we can carry out researches, readings and practices with meaning and purpose." (Aline)

"The classes were very important for me, because I was able to know the modality of presentation in poster and to familiarize myself a little more with the English language." (Jorge)

"O conteúdo da aula assim como a didática utilizada contribuíram em muito para a construção do poster em inglês." (Marina)

"Posso dizer que foi bastante positiva, uma vez que o conteúdo e a didática oferecida me possibilitou para a construção do poster em inglês." (Tiago)

Outras categorias de respostas que pudemos perceber foram as que mencionaram pontos positivos das aulas, mas que ao mesmo tempo evidenciaram a falta de domínio no idioma do próprio participante: 
"As aulas foram interessantes, bem direcionadas, porém a falta de domínio da língua dificultou a minha proatividade na atividade." (Samuel) "A proposta é boa. A dificuldade maior é o domínio do inglês." (Lucy) "Foram ótimas, para quem tem domínio do inglês, acho, acredito que ajudou bastante para essa exposição do poster." (Rosie)

"I think it's cool, but I do not speak English. I've had dificult." (Mara)

Interessante notar que a aluna Mara, que afirma não falar inglês, responde na língua-alvo em seu relato. Isso nos remete ao fato de que os aprendizes tendem à autoimposição de critérios de auto avaliação bastante duros para o que era esperado deles até mesmo pelo professor. Esse mesmo tipo de depoimento foi feito por outros aprendizes, como Chris, que nos diz: "I find it interesting, but I have a lot of difficulty in developing the activity, because I do not have any English skills". Ora, mesmo que a aluna tenha realizado pesquisas e traduções on-line de seus textos para as atividades serem completadas, por exemplo, esta é considerada uma forma de estudo e aprimoramento do idioma. É contraditório dizer, portanto, que ela não tenha nenhuma habilidade na língua inglesa.

Outra categoria percebida é a de que o curso estimulou os alunos a continuarem seu aperfeiçoamento na língua inglesa, como demonstramos nos relatos abaixo:

"Identifiquei a necessidade de retomar os estudos no inglês. Estimular minha leitura e explorar o idioma." (João)

"Well, at first I had some difficult because I stopped to study English some years ago. So the activity help me to decide to come back studying again. And say to me: English is very important..." (Joana)

"Achei bastante interessante, foi minha primeira experiência de curso online, dificuldades tive por não dominar o inglês, mas contribuiu bastante para a minha motivação para fazer outros cursos inclusive fiz matrícula no curso de inglês online." (Rosie - resposta para a pergunta 4)

Quanto às sugestões que os alunos nos deram em termos de melhoria do curso on-line, obtivemos respostas que remetem a:

- maior duração do curso para que o PPGTEG oriente mais os alunos,

- mais tempo para execução das atividades na plataforma,

- nivelamento dos alunos (alguns acreditam que o curso deveria ter sido mais "básico"); 
- mais uso de vídeos e recursos de áudio;

- uma "aula" explicando como usar a plataforma;

- feedbacks mais rápidos por parte das professoras pesquisadora e tutora;

- retirada das wikis.

A pergunta 7 teve como pressuposto saber se os alunos gostariam de continuar aprendendo inglês por meio de AS da esfera acadêmica (Would you keep on learning social activities in English for academic performance during your life as a student? Why?). Todos os 29 participantes que responderam ao questionário mencionaram que sim, gostariam. Eis algumas de suas respostas:

"Yes, I would. Because I would like to improve my knowledge during my life as a student." (Wilson)

"Sim. Acredito que é uma excelente oportunidade para adquirir aprendizado que servirá para aplicar na vida acadêmica quanto na própria vida." (Fabi)

"Yes, because the English language is universal. I am aware of my difficulty, however I want and need to break this paradigm that I can't learn this language." (Chris)

"Yes, it was an excellent experience. Because learning with a meaning/ objective bebind motivation and perfecting the result and product." (Aline)

A resposta de Aline evidencia o que falamos anteriormente sobre o principal dos objetivos de uma AS: o motivo-objeto. Este relato em particular nos mostra o grau de impacto dessa perspectiva em sala de aula no aprendizado dos alunos, que veem o processo de ensino-aprendizagem como relevante para suas vidas e focado em um objeto compartilhado entre todos os participantes. A aluna Liz nos diz:

"Certamente, é interessante para nosso aprendizado as atividades direcionadas e incentivadas para a participação nos congressos, seminários, fóruns. Excelente a iniciativa de partilhar com a comunidade acadêmica nossas pesquisas." (Liz - resposta à pergunta 7)

Essa afirmativa, além de funcionar como um impulso para que este curso tenha continuidade, resume o grande objetivo da TASHC e da AS proposta: permitir que os aprendizes se vejam não só no papel de alunos, mas no de pesquisadores que partilham com a comunidade acadêmica os resultados obtidos por suas pesquisas. 


\section{Reflexões finais e encaminhamentos}

Ao longo desta pesquisa-ação, desenvolvemos, implementamos e acompanhamos um curso de língua inglesa na EaD baseado em uma Atividade Social da esfera acadêmica. O principal objetivo, além de propor um curso mais democrático pelo fato de ser ofertado na modalidade a distância, foi contribuir para a área de ensino de línguas por meio de AS, que ainda não possui pesquisas detalhadas realizadas em contexto de AVEA.

Para alcançar os objetivos propostos nesta pesquisa, elaborei um planejamento inicial que espelhava o levantamento de necessidades que realizei com o curso do PPGTEG e com os aprendizes. Refleti também sobre a situação dos nossos alunos de graduação e pós-graduação que, em geral, possuem muita dificuldade quanto à performance em AS de cunho acadêmico: desde a inscrição em congressos, encontros, jornadas, até a elaboração de um pôster científico, que em geral é o gênero mais solicitado por tais eventos para alunos que não sejam de mestrado e doutorado ou que estejam com suas pesquisas em andamento.

O desenho do curso foi pensado para que as atividades didáticas tivessem um caráter colaborativo (enfatizado, ainda, por ser num ambiente virtual) e permitissem que os aprendizes enxergassem em sua execução o principal objeto da AS proposta: "apresentar pôster científico em um evento internacional". Esse objeto era da "vida que se vive" (MARX; ENGELS, 2006), de modo que a atividade de ensino-aprendizagem de LI se deu de modo autêntico e focado na participação dos alunos no EUTIC 2017, realizado em Recife - pela primeira vez fora da Europa.

Desse modo, o curso de curta duração (30 horas/aula) permitiu que os alunos pudessem se preparar para o evento, sentindo que teriam uma chance de participação cidadã em seu ambiente acadêmico. $\mathrm{O}$ aprendiz, então, teve a possibilidade de não ser excluído de seu meio, e ter o início de uma melhoria de vida cidadã, ideia que está de acordo com os preceitos da Linguística Aplicada que aqui adotamos e sobre os quais falamos em nossa fundamentação teórica.

Os objetivos propostos para a pesquisa foram alcançados e o que mais nos chamou atenção nesse processo foram os feedbacks dos aprendizes. Cremos que não seja possível pensar em ensino-aprendizagem baseado em AS e não levar em conta a voz e a tomada de decisão dos participantes nessa atividade, já que essa perspectiva considera os aspectos sócio-históricoculturais da AS. Portanto, muitas das atividades didáticas propostas foram 
avaliadas e serão readequadas para as próximas oportunidades em que o curso for ministrado.

Vimos pelas respostas dos alunos que o evento teve alguns deslizes quanto à confirmação do aceite dos trabalhos inscritos ter sido feita de última hora, problemas nas inscrições, e até mesmo quanto à organização como um todo. Além disso, alguns dos aprendizes, mesmo inscritos, não puderam viajar a Recife para apresentação do trabalho. São coisas da vida que se vive. No entanto, o que se pode dizer quanto ao planejamento didático ter sido realizado com o objeto da AS "apresentar pôster científico em evento internacional", é que esse tipo de plano não obriga o aprendiz a participar no objeto selecionado para a vida real. A função do objeto - o qual ele chama de motivo - é permitir que os indivíduos pertençam a determinado grupo social ao tentarem alcançar o mesmo objetivo, previamente definido a partir de uma necessidade observada e vivenciada. Leontiev (2004) trata desses objetivos como sendo parciais, pois eles, na verdade, definem o objeto da atividade conforme as vivências vão sendo experienciadas pelo grupo. "Assim, o sujeito vai se constituindo, nunca estando previamente formado, e esta constituição é histórica com a mediação do mundo como um todo" (LARRÉ, 2014, p. 77).

Pensando no que foi exposto, é possível dizer que AS são ações em que os indivíduos, em colaboração com os sujeitos que compõem a comunidade como um todo, interagem e modificam o mundo em que vivem. $\mathrm{Na}$ realidade da sala de aula, a produção de conhecimento, portanto, ocorre na relação e na interação entre as ações do cotidiano e o conhecimento científico; interação essa que pode acontecer "por meio de situações desafiadoras e mediante a descoberta de novos conceitos" (RODRIGUES, 2012, p. 51).

Em nossa pesquisa, esse conceito foi de fundamental importância, pois nos permitiu verificar a realização de modo "quase real" (LIBERALI, 2012) de AS que em um contexto escolar/acadêmico mais tradicional provavelmente não existiriam. Consideramos, assim como Liberali (2012), que participar de uma Atividade Social mediada por uma língua que não a sua materna, e que esteja dentro da realidade acadêmica, permite uma identificação do sujeito como cidadão do mundo, pois este espaço criado pela AS traz oportunidades de atuação perto das experiências extraacadêmicas que ele possivelmente vivenciará.

Para pesquisas futuras, será de fundamental importância investigar a natureza das interações estabelecidas nos fóruns, pois foi possível perceber 
uma expansão do conhecimento dos aprendizes do curso por meio do diálogo e compartilhamento de saberes, do aprimoramento dos aspectos enunciativos, linguísticos e discursivos no trabalho com os gêneros focais e orbitais, mas especialmente dos focais. Dentro da linha de pesquisa da argumentação escolar esse material é bastante rico em dados. Esperamos, portanto, que esses dados do curso possam servir para novas investigações, gerando possibilidade de pesquisa para estudantes da graduação e da pósgraduação e mais publicações relacionadas.

\section{Agradecimentos}

À Capes pela bolsa do Programa Nacional de Pós-doutorado (PNPD) que possibilitou a produção deste trabalho, assim como ao Programa de PósGraduação em Linguística da UFSCar, que me acolheu como pesquisadora. A Carla Richter, pelo olhar certeiro e leitura crítica da primeira versão deste artigo.

\section{Referências}

ALMEIDA FILHO, J. C. P. Quatro estações no ensino de linguas. Campinas: Pontes, 2012.

BARBIRATO, R. C. Planejamento baseado em tarefas subjacente a um material didático para o ensino de línguas: conceitos e compreensões reveladas. In: BARBIRATO, R. C.; SILVA, V. L. T. Planejamento de cursos de línguas: traçando rotas, explorando caminhos. São Paulo: Pontes, 2016. p. 117-142.

BOETTCHER, D. M. O ambiente EaD como possibilidade de complexificação da aprendizagem de língua inglesa. Revista Brasileira de Aprendizagem Aberta e a Distância, São Paulo, v. 7, p. 1-18, 2008. Disponível em: < https://bit.ly/2ImQXIq>. Acesso em: 8 mar. 2016.

CAVALARI, S. M. S. A autoavaliação da aprendizagem de inglês como língua estrangeira em um ambiente tandem a distância, RBLA, Belo Horizonte, v. 11, n. 1, p. 247-270, 2011. https://doi.org/10.1590/S1984-63982011000100013

DIAS, L. M. S. A expansão argumentativa na escrita de Multimodal Essays na graduação de Letras Lingua Inglesa. Dissertação (Mestrado em Linguística) - Universidade Federal de Pernambuco, Recife. 2018.

EMÍDIO, D. E. Planejamento temático baseado em tarefas no ensino e aprendizagem de inglês a distância. 2017. 335 f. Tese (Doutorado em Linguística) - Universidade Federal de São Carlos, São Carlos, 2017. 
ENGESTRÖM, Y. Perspectives on activity theory. Cambridge: Cambridge University Press, 1999. https://doi.org/10.1017/CBO9780511812774

ESTIVALET, G. L. O ensino e a aprendizagem da produção oral em língua estrangeira na educação a distância. 2012. Dissertação (Mestrado em Linguística) - Universidade Federal de Santa Catarina, Florianópolis, 2012.

ESTIVALET, G. L.; HACK, J. R. Ensino de língua estrangeira a distância: reflexões sobre o ensino/aprendizagem da habilidade oral. CONGRESSO INTERNACIONAL DA ABRALIN, 7., 2011, Florianópolis. Anais... Florianópolis: Universidade Federal de Santa Catarina, 2011. p. 1761-1775. Disponível em: < https://bit.ly/2L6uPjc > Acesso em: 20 mar. 2016.

FABRÍCIO, B. F. Linguística Aplicada como espaço de "desaprendizagem": redescrições em curso. In: MOITA LOPES, L. P. da (Org.). Por uma Linguística Aplicada indisciplinar. São Paulo: Parábola, 2006. p. 45-66.

FIGUEIREDO, F. J. Q. Aprendizagem de línguas estrangeiras: possibilidades de interação mediadas pelo computador. In: BARROS, D. M. et al. (Org.). O ensino em quatro atos: interculturalidade, tecnologia de informação, leitura e gramática. Campinas: Pontes, 2015. p. 163-188.

FREIRE, P. Pedagogia da autonomia. São Paulo: Paz e Terra, 1996.

LARRÉ, J. M. R. G. M. ...Câmera na mão! Argumentação e atividade social “elaborar documentários" na sala de aula de língua inglesa. 2014. Tese (Doutorado em Linguística) - Universidade Federal de Pernambuco, Recife, 2014. Disponível em: $<$ https://bit.ly/2KxPyeF>. Acesso em: 25 fev. 2016.

LEFFA, V. J. Aprendizagem mediada por computador à luz da Teoria da Atividade. Calidoscópio, São Leopoldo, v. 3, n. 1, p. 21-30, 2005.

LEONTIEV, A. A. O desenvolvimento do psiquismo. 2. ed. São Paulo: Centauro, 2004.

LEVAY, P. B. Jogos digitais no ensino e aprendizagem de inglês para crianças. 2015. Dissertação (Mestrado em Tecnologia e Gestão em Educação a Distância) Universidade Federal Rural de Pernambuco, Recife, 2015.

LIBERALI, F. C. Atividade social nas aulas de língua estrangeira. São Paulo: Moderna, 2009.

LIBERALI, F. C. (Org.). Inglês. São Paulo: Blucher, 2012. (Coleção A Reflexão e a Prática no Ensino, v. 2).

LIBERALI, A. R.; LIBERALI, F. Para pensar a metodologia de pesquisa nas ciências humanas. FAINC, Santo André, v. 1, n. 1, p. 17-33, jul./dez. 2011. 
LIMA, M. A. C.; MARTINS, P. L. O. Pesquisa-ação: possibilidade para a prática problematizadora com o ensino. Revista Diálogo Educacional, Curitiba, v. 6, n. 19, p. 51-63, set./dez. 2006. Disponível em: <https://bit.ly/2KynHvb>. Acesso em: 29 ago. 2017.

MOITA LOPES, L. P. da (Org.). Linguística Aplicada na modernidade recente: Festschrift para Antonieta Celani. São Paulo: Parábola, 2013.

MARX, K.; ENGELS, F. A ideologia alemã (1845-46). In: Arquivo Marxista na Internet, [s.l.], 2006. Disponível em: < https://bit.ly/1b44xuS>. Acesso em: 27 jan. 2016.

PAIVA, V. L. M. O. O papel da educação a distância na política de ensino de línguas. In: MENDES, E. A. M.; OLIVEIRA, P. M., BENN-IBLER, V. (Org.). Revisitações: edição comemorativa - 30 anos da Faculdade de Letras/UFMG. Belo Horizonte: UFMG/FALE, 1999. p. 41-57.

RICHTER, C. L. O ensino da lingua inglesa à luz. de Atividades Sociais na esfera acadêmica local: quando a linguagem, a língua e a universidade encontram-se para oferecer escolhas ao aluno da graduação. 2015. 277 f. Dissertação (Mestrado em Linguística) - Universidade Federal de Pernambuco, Recife, 2015.

RODRIGUES, P. A Atividade Social nas aulas de lingua espanbola: uma relação dialética entre a vida do aluno e o processo de ensino-aprendizagem. 2012. Dissertação (Mestrado em Linguística Aplicada e Estudos da Linguagem) - Pontifícia Universidade Católica de São Paulo, São Paulo, 2012.

RODRIGUES, S. J. S. EnglishGap: aplicativo móvel para o ensino de língua inglesa. 2014. Dissertação (Mestrado em Tecnologia e Gestão em Educação a Distância) - Universidade Federal Rural de Pernambuco, Recife, 2014.

SCHETTINI, R. H. et al. (Org.). Vygotsky: uma revisita no início do século XXI. São Paulo: Andross, 2009.

SILVEIRA, D. G. S. O ensino da língua inglesa à distância: caminhos e possibilidades. Revista Multitexto, Montes Claros, v. 3, n. 2, p. 28-32, 2015. Disponível em: < https:// bit.ly/2rPLTBq >. Acesso em: 1 mar. 2016.

Data de submissão: 02/01/2018. Data de aprovação: 07/05/2018. 